\title{
Studies on the Prevalence of Salmonella spp. in meat shop premises intended to sale meat for human consumption in North Kolkata, India
}

\author{
M. Saha, M. Saha*, C. Debnath, M. K. Biswas, A. K. Pramanik and D. Murmu \\ Department of Veterinary Public Health, WBUAFS, Kolkata, West Bengal, India \\ *Corresponding author
}

\begin{abstract}
A B S T R A C T
Keywords

Salmonella spp.,

Poultry meat,

Characterization, Antibiotic sensitivity.

\section{Article Info}

Accepted:

15 March 2016

Available Online:

10 April 2016

Salmonella is one of the most pathogenic genera implicated in food-borne bacterial outbreaks and diseases. There are numerous transmission routes for Salmonellosis, but the majority of the human infections are derived from consumption of contaminated foods especially those of animal origin. The study was undertaken to determine the incidence and distribution of salmonella species in poultry meat shop premises. A total no of 150 samples were procured from poultry shop premises in north Kolkata and analyzed for presence of salmonella strains. The study concluded that overall prevalence of salmonella species amongst all the samples as $4 \%$.All the eight salmonella isolates were subjected to antibiotic sensitivity test.In this method highest sensitivity was recorded against Ciprofloxacin $(83.33 \%)$ and Chloramphenicol(83.33\%) followed by Ampicillin, Cefotaxime, Ceftazidine, Nalidixic acid and Gentamicin(50\% each). Low sensitivity was observed against Tetracycline (16.66\%).
\end{abstract}

\section{Introduction}

Food-borne diseases are the main problem particularly in developing countries and cause the majority of illness and death around the World. Food is the most important vehicle that transmits microorganisms to human (Vernam, 1991). Among these micro-organisms salmonellae still a major cause of food-borne human diseases (Soultose et al., 2003; Carraminana et al., 2004). Poultry and poultry products are frequently contaminated with salmonellae that can be transmitted to human through the handling of raw poultry carcasses and products, or through consumption of undercooked poultry meat (Bailey and Cosby,2003; Kimura et al.,
2004). Salmonella outbreaks have been associated with improper cooking method, reheating of food and improper handling of food by food preparer (Gorman et al., 2002). Poultry meat is contaminated with salmonellae not only by infected poultry, but also by cross contamination with faeces, water, instruments and worker's hand during the slaughter process and handling. Chicken might thus provide the main transmission route of infection, especially with the increasing consumer demand for this food. Salmonella species are a leading bacterial cause of acute gastroenteritis. These are of great concern because of their ability to 
cause large outbreaks of food borne illnesses involving a variety of foods of plant and animal origin (Holley, 2011). Nevertheless, foods of animal origin such as eggs, poultry, pork or beef are generally associated with the transmission of this bacterial species (Pires et al., 2010; Callaway et al., 2008; Braden, 2006).

Considering the aforesaid aspects, the present study was carried out to generate data on prevalence, isolation and characterization of Salmonella spp. from meat shop premises in North Kolkata.

\section{Materials and Methods}

Materials for this investigation were collected from North Kolkata, West Bengal. For this study, altogether 150 samples were collected randomly from various retails meat shops premises. Samples were collected aseptically by cotton swabs and kept in the sterile vial with NSS for further use. All the materials immediately after collection were placed inside a thermo flask containing ice cube for transportation into the laboratory for examination.

\section{Inoculum Preparation}

Each sample from same poultry meat premises were pooled and pasted in a separate pastle and morter with $10 \mathrm{ml} \mathrm{NSS}$ and thoroughly suspended with the help of pastle and morter. Then about $5 \mathrm{ml}$ of this suspension was added aseptically into the enrichment media Selenite F. broth (HiMedia) with the help of a sterile pipette and incubated at $37^{\circ} \mathrm{C}$ for $24 \mathrm{hrs}$ after that a loopful of inoculums from the broth was streaked directly on Macconkey's agar, Salmonella shigella agar and Brilliant Green agar plate (Hi-Media) separately and incubated at $37^{\circ} \mathrm{C}$ for $24-48 \mathrm{hrs}$ respectively.

\section{Identification of Salmonella spp}

Colonies of salmonella strains appeared colourless, translucent to opaque and generally irregular edge on Macconkey's agar and opaque, translucent, uncoloured colonies or sometimes black centered colonies on salmonella shigella agar were considered as presumptive of salmonella spp.

Morphologically typical colonies were identified by Gram Staining, Motility test and Biochemical screening test were performed as per method described by Edward and Ewing (1972) and Cruickshank et al. (1975). The following Biochemical tests were performed such as Triple sugar iron agar, IMVIC, Citrate Utilization test, Urease and Sugar Fermentation test for confirmation of salmonella spp.

\section{Results and Discussion}

The present work was undertaken in order to characterize the isolates of Salmonella spp. from poultry. This investigation work was undertaken during the period from April, 2011 to September, 2011. Altogether 150 samples were examined for isolation of the salmonella spp.

Out of 150 samples 6(4\%) samples were found to be contaminated with salmonella. Dasgupta, 1975, also isolated $2.36 \%$ salmonellae from poultry meat samples which were correlated with the findings of present study. It was also reported that $7.66 \%$ salmonella from poultry was isolated by Nag and Koley (1986) which is partially correlated with this finding. Roy. P. et al; (2002) also isolated $11.99 \%$ salmonella from poultry products, poultry environment and other sources. 


\section{Characterization of the Isolates}

In the present study, all the six Salmonella isolates were examined for culture and morphological characterization and were Biochemically screened by TST, IMVIC tests, Nitrate reduction and $\mathrm{H} 2 \mathrm{~S}$ Production test, indole, citrate and motility test. All the isolates were typical in their characters, i. e., produced typical colonies on Macconkeys agar and BGA agar. All the isolates were constantly motile and gram negative, short rod in their staining reaction. The above finding correlated with Edward and Ewing (1972).The Biochemical characters of the isolates were typical to the genus. All the isolates were indole negative and produced $\mathrm{H} 2 \mathrm{~S}$, reduced nitrate. $\mathrm{H} 2 \mathrm{~S}$ production was observed in five $(83.33 \%)$ of the isolates. All produced typical acid but (yellow) and alkaline slant (pink) in TST agar. The other observation in this study was accordance with Santu Das (2002). In sugar fermentation reaction, all the 6 isolates fermented glucose, maltose and manitol but negative to lactose, sucrose and salicin. The above results correlated with Edward and Ewings (1972) and other workers like Jana et al. (1995) and Santu Das (2002).

\section{Antiobiotic Sensitivity of Salmonella}

Total 150 samples were subjected for isolation of the salmonella spp. from different poultry meat shop premises. Out of 150 samples, altogether six isolates of salmonella spp. were isolated and tested for their sensitivity to eight different antimicrobial drugs commonly used in veterinary practice. The result of sensitivity and resistant pattern of the strains to different antimicrobial drugs were presented as follows-

Table.1 Biochemical Reaction of Salmonella Isolates

\begin{tabular}{|c|c|c|c|c|c|c|c|c|c|c|}
\hline \multirow[b]{2}{*}{ ڤ⿱艹 } & \multirow[b]{2}{*}{ 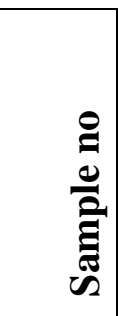 } & \multicolumn{4}{|c|}{ Reaction on TSI Agar } & \multirow[b]{2}{*}{$\begin{array}{l}\bar{E} \\
\sum_{\bar{E}}^{e}\end{array}$} & \multirow[b]{2}{*}{ 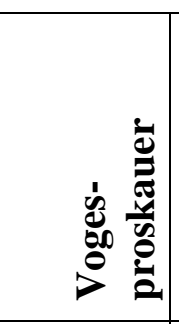 } & \multirow[b]{2}{*}{ 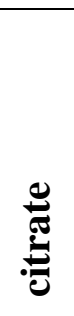 } & \multirow[b]{2}{*}{$\frac{1}{2}$} & \multirow[b]{2}{*}{ 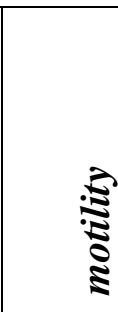 } \\
\hline & & $\bar{E}$ & $\frac{\vec{\Xi}}{\omega}$ & 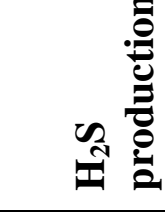 & 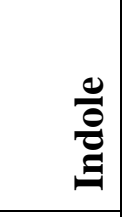 & & & & & \\
\hline 1 & T1 & Acid & Alk & + & - & + & - & + & - & + \\
\hline 2 & T2 & Acid & Alk & + & _ & + & - & + & _ & + \\
\hline 3 & T3 & Acid & Alk & - & _- & + & - & + & - & + \\
\hline 4 & T4 & Acid & Alk & + & - & + & - & -3 & - & + \\
\hline 5 & T5 & Acid & Alk & + & & + & _ & + & _ & + \\
\hline 6 & T6 & Acid & Alk & + & & + & & + & & + \\
\hline
\end{tabular}


Table.2 Sugar Fermentation Test of Salmonella Isolates

\begin{tabular}{|c|c|c|c|c|c|c|c|}
\hline Sample no & Glucose & Lactose & Maltose & Sucrose & Manitol & Salicin & Sorbitol \\
\hline T1 & + & - & + & - & + & - & + \\
\hline T2 & + & - & + & - & + & - & + \\
\hline T3 & + & - & + & - & + & - & + \\
\hline T4 & + & - & + & - & + & - & + \\
\hline T5 & + & - & + & - & + & - & + \\
\hline T6 & + & - & + & - & + & - & + \\
\hline
\end{tabular}

Table.3 Sensitivity and Resistant Pattern of Isolated Salmonella Strains

\begin{tabular}{|l|c|c|c|c|c|c|c|}
\hline \multirow{2}{*}{$\begin{array}{l}\text { Antimicrobial } \\
\text { agent }\end{array}$} & \multirow{2}{*}{ No. of isolates } & \multicolumn{6}{|c|}{ Salmonella strains } \\
\cline { 3 - 8 } & & \multicolumn{2}{|c|}{ resistant } & \multicolumn{2}{c|}{ intermediate } & \multicolumn{2}{c|}{ sensitive } \\
\cline { 3 - 8 } & & No. & $\%$ & No. & $\%$ & No. & $\%$ \\
\hline Ampicillin & 6 & 2 & 33.33 & 1 & 16.66 & 3 & 50 \\
\hline Ciprofloxacin & 6 & - & - & 1 & 16.66 & 5 & 83.33 \\
\hline Chloramphenicol & 6 & 1 & 16.66 & - & - & 5 & 83.33 \\
\hline Ceftazidine & 6 & 1 & 16.66 & 2 & 33.33 & 5 & 50 \\
\hline Cefotaxime & 6 & 2 & 33.33 & 1 & 16.66 & 3 & 50 \\
\hline Nalidixic acid & 6 & 1 & 16.66 & 2 & 33.33 & 3 & 50 \\
\hline Tetracycline & 6 & 5 & 83.33 & - & - & 1 & 16.66 \\
& & & & & & & \\
\hline Gentamicin & 6 & 2 & 33.33 & 1 & 16.66 & 3 & 50 \\
\hline
\end{tabular}

From Table 3 it could be noted that highest sensitivity was recorded against Ciprofloxacin $\quad(83.33 \%)$ and Chloramphenicol (83.33\%) followed by Ampicillin, Cefotaxime, Ceftazidine, Nalidixic acid and Gentamicin (50\% each). Low sensitivity was observed against Tetracycline (16.66\%).

The above finding $s$ were partially corroborated with Ghosh (1992) who reorted that salmonella spp. were highly sensitive to chloramphenicol and nalidixic acid. Verma et al. (1993) showed $97.37 \%$ sensitivity against chloramphenocol and nalidixic acid. The highest resistance to salmonella strains was recorded against tetracycline $(83.33 \%)$ followed by ampicillin, cefotaxime and gentamycin $(33.33 \%$ each). The lowest resistant was recorded against ciprofloxacin followed by chloramphenicol, ceftazidine, nalidixic acid (16, 66\% each). The above findings were partially corroborated with Manie et al. (1998) who detected resistance of salmonella spp. against tetracycline. Rajshekara et al. (2006) also showed resistance against tetracycline.

The study concluded that samples collected from various meat shop premises indicate a very low prevalence; there is no scope of complacency. It requires continuous surveillance of situation including the antimicrobial resistance pattern.

\section{References}

Bailey, J.S., Cosby, D.E. 2003. Detection of Salmonellae from chicken rinses and chicken hot dogs with automated Bax PCR system. J. Food Protect., 66: 2138-2140. 
Braden, C.R. 2006. Salmonella enterica serotype enteritidis and eggs: A national epidemic in the United States. Clin. Infect. Dis., 43: 512 517.

Callaway, T.R., Edrington, T.S., Anderson, R.C., Byrd, J.A., Nisbet, D.J. 2008. Gastrointestinal microbial ecology and the safety of our food supply as related to Salmonella. J. Ani. Sci., 86: E163-E172.

Carraminana, J.J., Rota, C., Agustin, I., Herrera, A. 2004. High prevalence of multiple resistance to antibiotics in Salmonellae serovars isolated from a poultry slaughterhouse in Spain. Vet. Microbiol., 104: 133-139.

Cruickshank, R., Dugid J.P., Marmion, B.P., Swain, R.H.A. 1975. Medical Microbiology: The Practice of Medical Microbiology.12th edition. Vol. II, Churchil Livingstone, Editnburg, London.

Dasgupta, P. 1975. Incidence of salmonella in poultry meat in West Bengal and its public health importance. Indian Vet. J., 53: 567.

Das, S. 2000. Isolation and Characterization of Staphylococcus sp. (coagulase positive) and salmonella sp. From poultry and buffalo meat with special reference to the pathogenicity and antibiogram. A Thesis (M.V.Sc) submitted to the department of veterinary microbiology, West Bengal university of Animal and Fishery science, Kolkata-700037.

Edward, P.R., Ewing, W.H. 1972. Identification of Enterobacteriaceae, 3rd edn. Burgess Publication Company, Minneapolis, Minnesota.

Holley, R.A. 2011. Food safety challenges within North American Free Trade Agreement (NAFTA) partners. Comprehensive Reviews in Food Science and Food Safety, 10: 131-
142.

Ghosh, S.S. 1998. Drug resistance pattern of Salmonella Virchow 6,7: 1,2 isolated from poultry in North Eastern Region. Indian Vet. J., 65(12): 11511153.

Gorman, R., Bloomfield, S., Adley, C. C. 2002. A study of crosscontamination of food-borne pathogens in the domestic kitchen in the Republic of Ireland. Int. J. Food Microbiol., 76: 143-150.

Jana, S.K., Roy, J.P., Nag, N.C. 1995. Isolation of salmonella from poultry in and around Calcutta. Indian $J$. Ani. Health, 32(2): 95-96.

Kimura, A.C., Reddy, V., Marcus, R. 2004. Chicken consumption is a newly identified risk factor for sporadic Salmonellae enteric serotype enteritidis infections in the United State. Clin. Infect. Dis., 38: 244-252.

Manie, T., Khan, S., Brozel, V.S., Veith, W.J., Gouws, P.A. 1998. Antimicrobial resistance of bacterial isolated from slaughter and retail chicken in south Africa. Lett. Appl. Microbial., 26: 253-258.

Nag, N.C., Koley, B. 1986. Isolation of salmonella from poultry in Calcutta. Indian J. Animal Health, 25: 101.

Pires, S.M., Vigre, H., Makela, P., Hald, T. 2010. Using outbreak data for source attribution of human salmonellosis and campylobacteriosis in Europe. Food borne Pathogens and Dis., 7: 1351-1361.

Roy, P., Dhillon, A.S., Lauerman, L.H., Schaberg, D.M., Bandli, D., Johnson, S. 2002. Results of Salmonella isolation from poultry products, poultry, poultry environme nt and other characteristics. Avian Dis., 46(1): 17-24.

Rajashekara, G., Haverly, E., Halvorson, D.A., Ferris, K.E., Lauer, D.C., 
Nagaraja, K.V. 2000. Multidrugresistant Salmonella typhimurium DT104 in poultry. J. Food Protection, 63: 155-161.

Soultose, N., Koidis, P., Madden, R.H. 2003. Prevalence of Listeria and Salmonellae in retail chicken in Northern Ireland. Appl. Microbiol.,
37: 421-423.

Verma, S.C., Gupta, B.R., Ghosh. 1993. Studies on Salmonella virchew: in vetro sensitivity. Indian Vet. J., 70.

Varnam, A.H. 1991. Food borne Pathogens, 1st. Edn., Wolfe Publication Ltd., pp. 71-76.

\section{How to cite this article:}

Saha, M., M. Saha, C. Debnath, M. K. Biswas, A. K. Pramanik and Murmu, D. 2016. Studies on the Prevalence of Salmonella spp. in meat shop premises intended to sale meat for human consumption in North Kolkata. Int.J.Curr.Microbiol.App.Sci. 5(4): 297-302. doi: http://dx.doi.org/10.20546/ijcmas.2016.504.034 